\title{
MULTIPLE PITUITARY HORMONE DEFICIENCY CAUSED BY PIT-I MUTATION AND THE CHALLENGES OF MANAGEMENT IN A DEVELOPING COUNTRY
}

\author{
${ }^{1,3}$ Ayoola O.O, ${ }^{1}$ Oladejo F.A, ${ }^{2}$ Dattani $M$ and ${ }^{3}$ Clayton P.E
}

${ }^{1 .}$ Department of Paediatrics, University College Hospital, Ibadan. ${ }^{2 .}$ Department of Paediatric Endocrinology, Institute of Child Health, London. ${ }^{3}$ Department of Endocrinology, Royal Manchester Children's' Hospital, Manchester, United Kingdom

Correspondence

Dr. Omolola. O. Ayoola

Department of Paediatrics,

University College Hospital,

Ibadan

Email: ooayoola@yahoo.com

\begin{abstract}
Background: In most developing countries, childhood endocrine disorders are not as common as infections but they do occur. Multiple pituitary hormone deficiency (MPHD) is a known cause of familial short stature. This is very rarely diagnosed in Nigerian children.

We describe the challenges of diagnosis and management of childhood endocrine conditions in a developing economy using a ten year old Nigerian girl with MPHD as an illustration.

Methods: Patient had auxological data suggestive of short stature. In order to make a definitive diagnosis, pituitary function tests were carried out in the United Kingdom.

Results: Biochemical tests revealed growth hormone (GH) deficiency, Thyroid Stimulating Hormone (TSH) deficiency, decreased prolactin (PRL) level, normal cortisol and gonadotrophins. Her DNA analysis identified PIT-1 mutation in exon-6. She was placed on recombinant $\mathrm{GH}$ and thyroxine with evidence of catch up in height.

Conclusions: There were challenges to management such as, inadequate facility for diagnosis, huge cost of treatment and little awareness about childhood endocrine conditions amongst health workers in a developing economy.
\end{abstract}

Keywords: Multiple pituitary hormone deficiency (MPHD), PIT-1 mutation, short stature, management, developing country.

\section{INTRODUCTION}

Endocrine disorders do occur among children in developing countries, despite the high prevalence of infectious diseases and malnutrition. Reports of endocrine disorders in children in developing countries are few compared to developed countries reflecting the different level of prevalence in the different geographical locations and or level of awareness and availability of facilities for proper diagnosis.

Multiple Pituitary Hormone Deficiency (MPHD) is an endocrine disorder that causes short stature. It may occur as a result of acquired lesions in the hypothalamo-pituitary area such as tumour, surgery, trauma, or irradiation. They may also be idiopathic or result from genetically defined conditions. Congenital MPHD may be familial in $10 \%$ of cases, but they are usually sporadic ${ }^{1}$.

MPHD is characterized by impaired production of $\mathrm{GH}$ and one or more of the other pituitary hormones. Some developmental genes that play critical role in cell proliferation, cell differentiation and organ commitment such as Hesx1, Lhx3, Lhx4, Prop1, PIT$1, \mathrm{SO} 3$ and Sox 2 have been implicated in $\mathrm{MPHD}^{2}$. These genetic mutations and their inheritance were first shown in mice and then in humans. They present with variable phenotypes ${ }^{2}$.

The PIT-1 gene, the first pituitary-specific transcription factor to be identified in the mouse and human, encodes the POU-domain transcription factor PIT-1 which plays a major role in the normal development of the anterior pituitary gland ${ }^{3-4}$. It is a 291-aminoacid protein that is essential for the expression of the PRL, GH and TSH genes ${ }^{3-4}$. PIT-1 is also required for both specification and proliferation of somatotrophs, lactotrophs and thyrotrophs to a limited extent ${ }^{4}$. Therefore, PIT-1 mutations are associated with GH, PRL and TSH deficiencies with TSH being highly variable $^{2}$. 
There is very limited data on this condition in Nigerian children. We use this case to illustrate the challenges of diagnosis, management and of follow up of this treatable endocrine condition in a developing country and the implications for children with childhood endocrine conditions in general.

\section{Patient}

Informed consent was obtained from the child and her parents. This 10 year old girl was first referred at
Parents became worried about her growth from the time she was 2 months of age. She was said to be feeding well. Stool and bowel motions were normal. No episodes of recurrent diarrhoea and/or vomiting. She had no history of chronic cough or breathlessness and she had completed all childhood immunizations. Her developmental milestones were within normal limits.

\begin{tabular}{|l|l|l|l|l|l|l|}
\hline $\begin{array}{l}\text { Decimal } \\
\text { Age }\end{array}$ & $\begin{array}{l}\text { Height } \\
(\mathrm{cm})\end{array}$ & $\begin{array}{l}\text { Keight } \\
(\mathrm{kg})\end{array}$ & BMI & HeightSDS & WeightSDS & BMSDS \\
\hline 289 & 72 & 8 & 154 & -608 & -5.38 & -0.40 \\
\hline 5.23 & 82.6 & 11.6 & 17.3 & -6.10 & -4.16 & 1.10 \\
\hline 7.34 & 95 & 18 & 19.9 & -5.39 & -206 & 1.80 \\
\hline
\end{tabular}

Table 1: Growth Pattem over 4 years

the age of 2 years on account of poor growth from birth. She was born at term by spontaneous vaginal delivery, after an uneventful pregnancy. Her birth weight was $2.8 \mathrm{~kg}$ but her birth length was not recorded. Neonatal period was normal.
She is the third of three children. Older siblings are of normal height and weight. There is a positive history of short stature in her paternal grandfather. Father's height is $178 \mathrm{~cm}$ and mother's height is $153 \mathrm{~cm}$. She has a mid parental height around the $25^{\text {th }}$ centile.

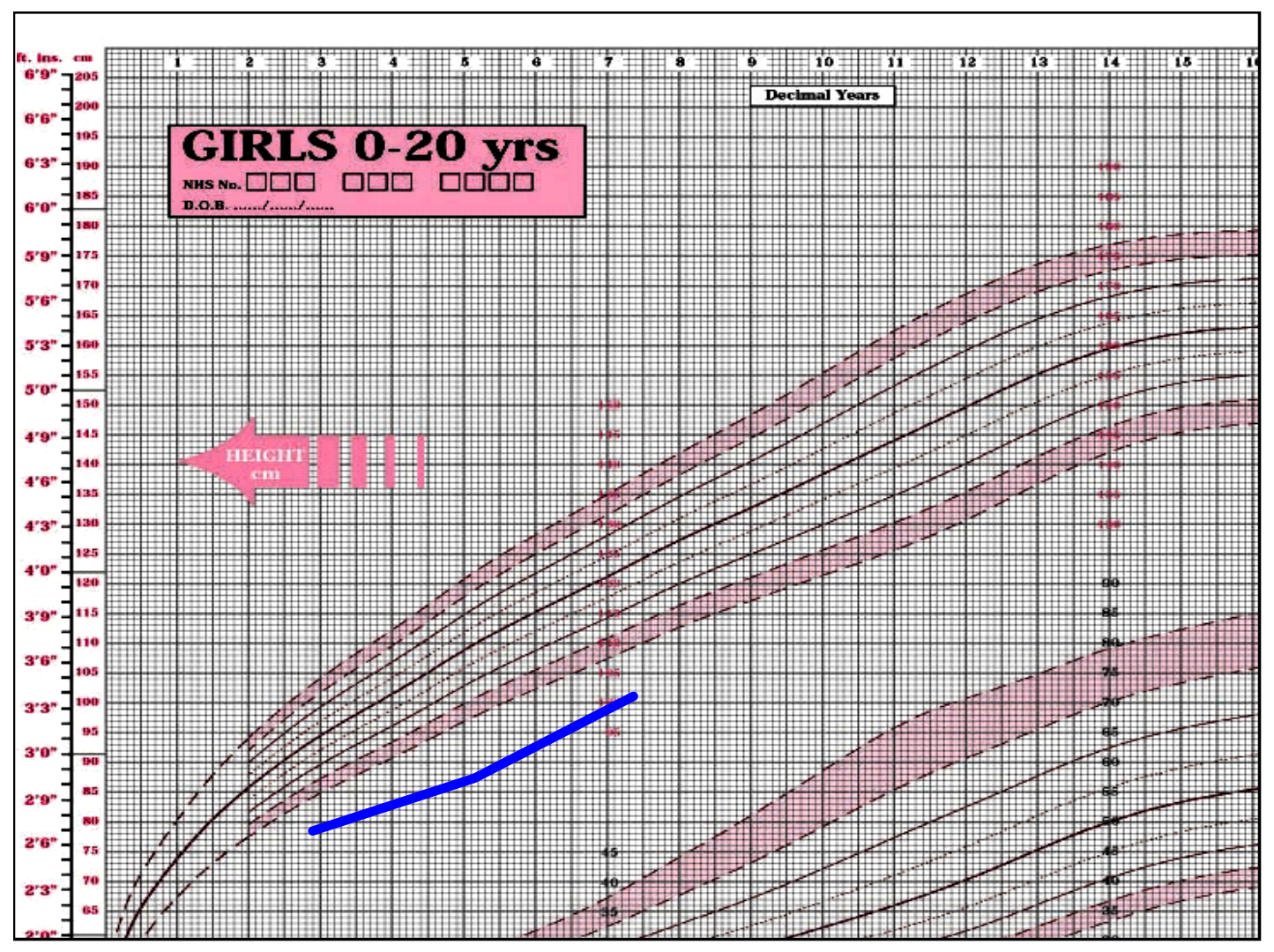

Figure 1: Subject's Growth Chart show ing heightvelocity from $2-7$ years of age 
At presentation, she was small for age. She weighed $8 \mathrm{~kg}$ with a height of $72 \mathrm{~cm}$, which was $<0.4^{\text {th }}$ centile for age. Investigations such as chest radiograph, electrocardiography, full blood count, urine culture and urinalysis were all normal. Her haemoglobin electrophoresis is A. Random blood sugar was $49 \mathrm{mg} /$ $\mathrm{dl}$, within normal limits. Electrolytes and urea were normal.

At 5 years, her weight was $11.6 \mathrm{~kg}$ (-4.2 standard deviation score [SDS]) her height was $82.5 \mathrm{~cm}(-6.1$ SDS). She had subtle features of GH deficiency. She had a prominent forehead with flat nasal bridge and a rather high palate. She has almond shaped eyes. Her hands and feet were rather cool. Her cardiovascular system was otherwise normal. Her nails were normal but she had short fourth and fifth metacarpals. She had a very prominent fatty abdomen with fatty breasts and a marked lumbar lordosis. Other systems were normal.

She remained markedly short, $95 \mathrm{~cm}(-5.4 \mathrm{SDS})$ and had become overweight at 7 years with body mass index (BMI) SDS of 1.8. Table 1 shows her growth pattern over four years. Parents reported that she had developed some psychosocial problems. She had become very conscious of her extreme short stature, she was shy and sometimes manipulative. Figure 1 shows her growth chart with growth velocity from the age of 2.9 years to 7.3 years.

A diagnosis of marked short stature was made but the cause was not defined. The following differential diagnoses were considered, skeletal dysplasia, storage disorder (mucopolysaccharidosis) and GH deficiency. Further investigations were required for which facilities were not available in Nigeria. He was subsequently referred to and reviewed at the Royal Manchester Children Hospital, Manchester, United Kingdom in order to make a definitive diagnosis of the cause of her short stature.

\section{RESULTS}

Table 2 is a summary of the anterior pituitary function tests carried out at Royal Manchester Children Hospital, Manchester, United Kingdom. The results revealed

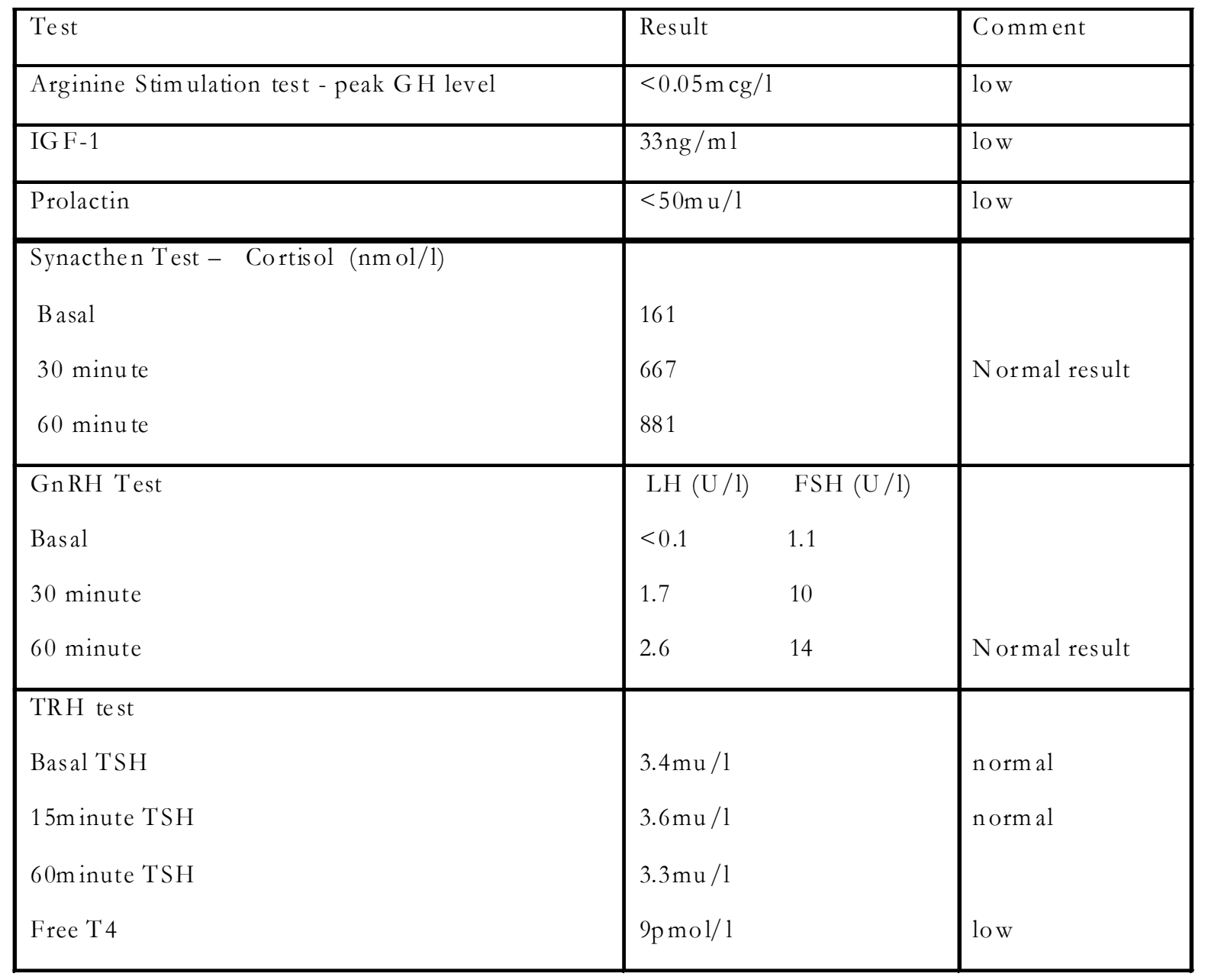

Table 2: Su mmary of Pituitary Investigations in the United Kingdom 
peak $\mathrm{GH}<0.05 \mathrm{mcg} / 1$ with arginine stimulation test, IGF-I was $33 \mathrm{ng} / \mathrm{ml}$ (low) and prolactin was $<50 \mathrm{mU} /$ 1 (low). TRH test revealed low free $\mathrm{T}_{4}$ of $9 \mathrm{pmol} / 1$, normal basal TSH of $3.4 \mathrm{mU} / 1$ and $3.3 \mathrm{mU} / 1$ at 60 minutes. There was normal cortisol and gonadotrophins.

These results indicated severe GH deficiency, low thyroxine with a normal basal TSH and a pituitary response to Thyrotropin-releasing hormone (TRH), undetectable prolactin, but normal cortisol response to synacthen and gonadotrophins responses to Gonadotropin-releasing hormone $(\mathrm{GnRH})$. These results are consistent with PIT-1 deficiency. A DNA sample was sent to screen for PIT-1 gene mutations by DNA sequencing. that there was improvement in the psychosocial problems associated with short stature in this child.

\section{DISCUSSION}

In Nigeria, despite the high burden of childhood infections, endocrine diseases are not uncommon. The Coventry Consensus in 1998 recommended a single height measurement of all children at school entry or around the age of 5 years and prompt referral of children with height less than 0.4 th centile for further assessment, in order to identify undetected and treatable asymptomatic growth disorders. ${ }^{5}$ This is not carried out routinely as recommended in Nigeria as in many other African countries. Therefore, many cases of short stature are undiagnosed and there is very little data on short stature in Nigerian children. In 1992,

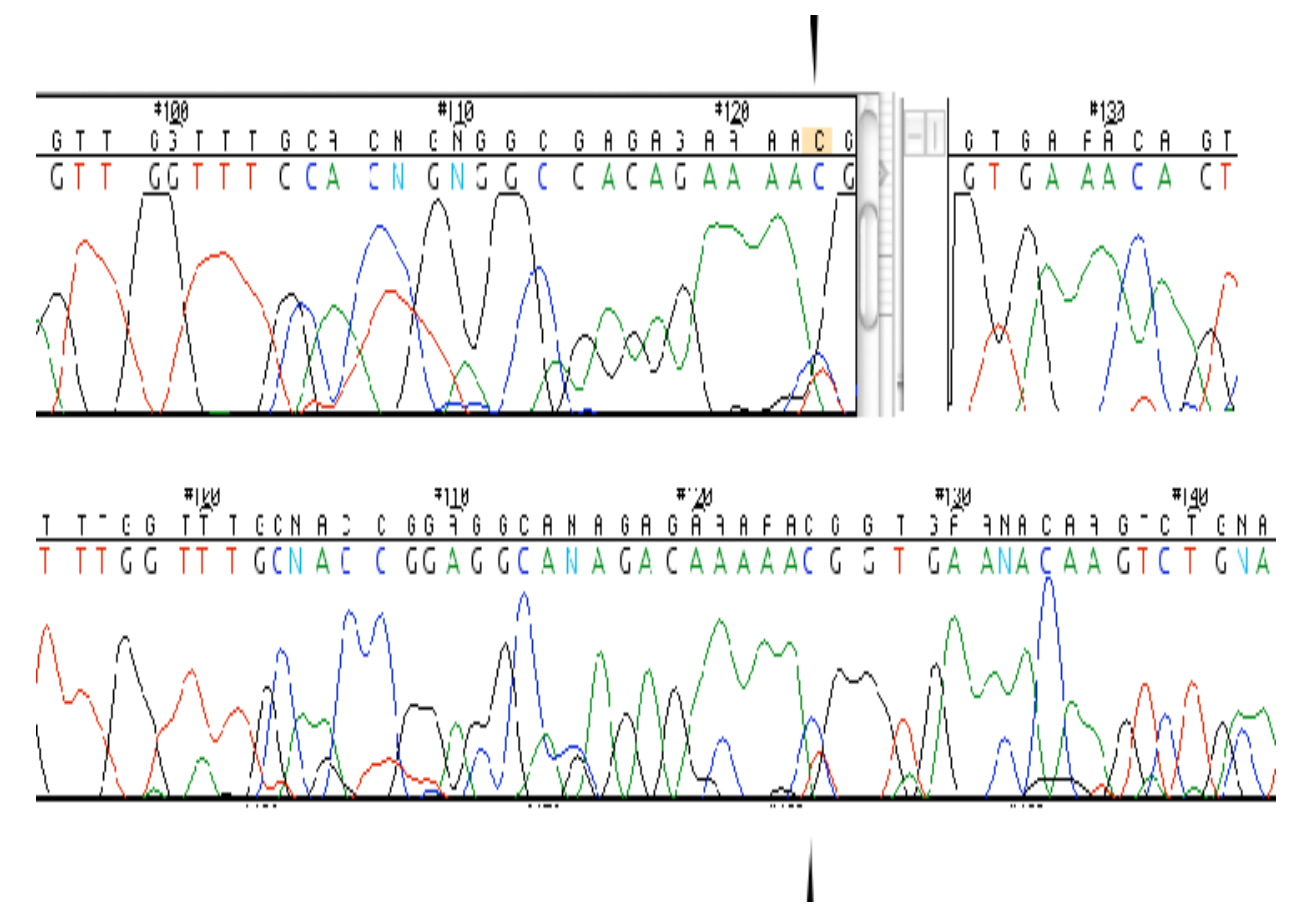

Figu re 2: Result of DNA Analysis for PIT-I Mutation

- Heterozygous $c>t$ change indicated by arrow

- $\quad(\operatorname{cg} g>\operatorname{tg} g, \mathrm{R}>W)$

- Dominant mutation in PIT-1

Figure 2 shows the result of the DNA analysis for PIT-I Mutation. There was heterozygous $\mathrm{c}>\mathrm{t}$ change (cgg $>$ tgg, R $>$ W) . The dominant mutation was in PIT1 showing R271W mutation in exon 6.

The patient was subsequently commenced on thyroxine $75 \mathrm{mcg}$ daily and $\mathrm{GH}$ at $0.031 \mathrm{mg} / \mathrm{kg}$ daily. Table 3 shows her growth pattern over 13 months of GH therapy. Her height had increased by about $12 \mathrm{~cm}$. At the age of 10 years, her height was $117 \mathrm{~cm}$, which is (3.2SDS). Figure 3 illustrates the catch up in height evidenced by crossing of centiles on the growth chart. In addition to catch up in height, parents also reported

Famuyiwa reported 24 cases of short stature in Ibadan, Nigeria. This was a descriptive study as no hormonal data was available in most of the patients and in 4 of them, the cause of the short stature could not be determined. Five of the children were also reported to have idiopathic hypopituitarism. It was not possible to define the cause of the hypopituitarism as we have done in the case reported because of lack of facility. Unlike this reported case, most of them presented first in adolescence. ${ }^{6}$

Short stature is not a rare condition in childhood. Early diagnosis is very essential for prompt institution of therapy to enable short children to catch up and achieve normal height. 
There are no known reported cases of combined pituitary hormone deficiency in Nigerian children. This is not because these cases are non-existent but due to low level of awareness among health care providers and lack of facilities for diagnosis. This child with PIT1 mutation is evidence that this condition occurs in African children.

PIT-1 mutations were first described in 1992 by four independent groups ${ }^{7-10}$. Several mutations have been
There was lack of facility in Nigeria for definitive diagnosis in this patient. In addition, her parents have to pay for growth hormone therapy. This is a very huge burden for them. The use of GH was evidently of immense value in this patient, not only to make her grow taller, but it contributed to the improvement in the psychosocial problems associated with short stature in this child, enhancing adaptation to a better social life in adulthood.

\begin{tabular}{|l|l|l|l|l|l|l|}
\hline $\begin{array}{l}\text { Decimal } \\
\text { Age }\end{array}$ & $\begin{array}{l}\text { Height } \\
(\mathrm{cm})\end{array}$ & $\begin{array}{l}\text { Weight } \\
(\mathrm{kg})\end{array}$ & BMI & HeightSDS & WeightSDS & BM ISDS \\
\hline 8.82 & 105.5 & 20 & 18.1 & -4.57 & -2.35 & 0.80 \\
\hline 9.43 & 107 & 30.5 & 26.6 & -4.66 & 0.04 & 2.83 \\
\hline 9.73 & 117 & 34.5 & 25.2 & -3.21 & 0.52 & 2.52 \\
\hline
\end{tabular}

Table 3: Growth Parameters after starting rhGH

described subsequently, with a total of twenty- one mutations described to date, and the most frequent being the dominant $\mathrm{R} 271 \mathrm{~W}$ mutation ${ }^{10-12}$.
Furthermore, there were other logistic problems with management and follow-up of this patient. GH was

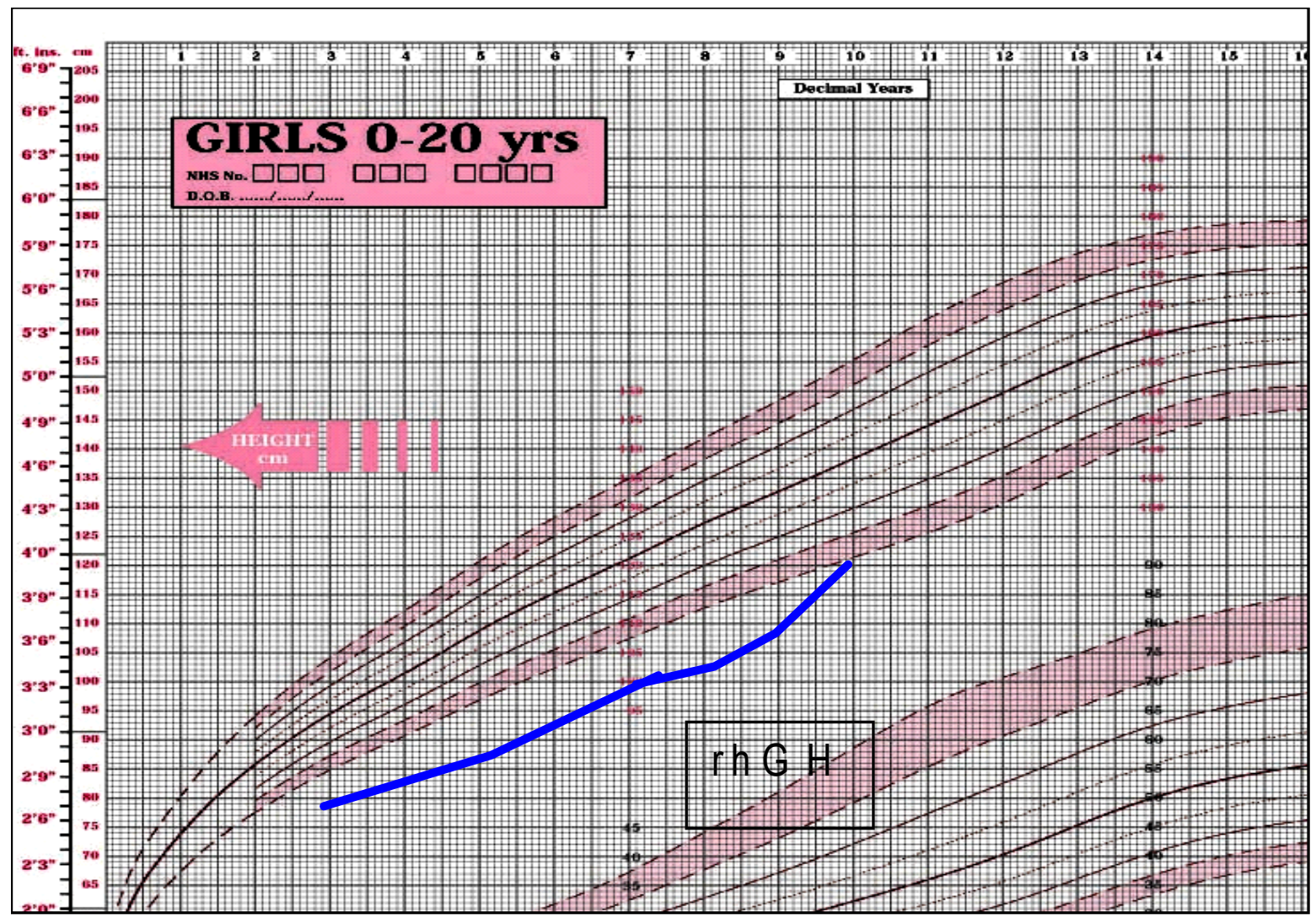

F ig u re 3 
not available in Nigeria and we had to procure it from the United Kingdom. There were also problems with storage of GH, which should be kept refrigerated. There is incessant electricity power cut in the country which can jeopardize the quality and efficacy of GH. There is the need for the policy makers and the government not only to be committed to provision of appropriate equipment and facilities for the diagnosis and management of childhood endocrine disorders in the country but also the management of non-communicable disorders in general. GH and other hormones should be made available in the country so that the cost of shipment can be eliminated.

Furthermore, health care providers in developing countries should have a high index of suspicion when patients present with short stature.

In conclusion, $\mathrm{GH}$ therapy has been beneficial for catch up in height in this child. It also improved the psychosocial problems associated with short stature thereby enhancing adaptation to a better social life in adulthood. For the Nigerian child; there are challenges to achieving these goals. The health care providers and the policy makers in Nigeria and other developing countries have an important, significant and urgent role to play in order to improve the outlook and quality of life for African children with endocrine disorders.

\section{REFERENCES}

1. Procter AM, Phillips IJA, and Cooper DN. The molecular genetics of growth hormone deficiency. Hum Genet 1998; 103:255-272.

2. Kelberman D., and Dattani MT. Hypopituitarism oddities: congenital causes. Hormone Research. 2007; 68:138-144.

3. Rosenfeld MG., POU-domain transcription factors: pou-er-ful developmental regulators. Genes Dev. 1991; 5:897- 907.

4. Theil LE, and Karin M, Transcriptional control of GH expression and anterior pituitary development. Endocr Rev. 1993; 14:670-689.

5. Grote FK, Oostdijk W, De Muinck KeizerSchrama SM, Dekker FW, van Dommelen P, van Buuren S, Lodder-van der Kooij AM, Verkerk $\mathrm{PH}$, and Wit JM. Referral patterns of children with poor growth in primary health care. BMC Public Health. 2007; 7: 77.

6. Famuyiwa OO. Short stature at the University College Hospital, Ibadan, Nigeria. West Afr J Med. 1992;11:62-71.

7. Ohta K, Nobukuni Y, Mitsubuchi H, Fujimoto S, Matsuo N, Inagaki H, Endo F, and Matsuda I. Mutations in the PIT-1 gene in children with combined pituitary hormone deficiency. Biochem Biophys Res Commun 1992; 189:851-855.

8. Tatsumi K, Miyai K, Notomi T, Kaibe K, Amino $\mathrm{N}$, Mizuno $\mathrm{Y}$, and KohnoH. Cretinism with combined hormone deficiency caused by a mutation in the PIT1 gene. Nat Genet 1992; 1:5658

9. Pfaffle RW, DiMattia GE, Parks JS, Brown MR, Wit JM, Jansen M, Van der Nat H, Van den Brande JL, Rosenfeld MG, and Ingraham HA. Mutation of the POU-specific domain of PIT-1 and hypopituitarism without pituitary hypoplasia. Science 1992; 257:1118-1121

10. Radovick S, Nations M, Du Y, Berg LA, Weintraub BD, and Wondisford FE. A mutation in the POU-homeodomain of PIT-1 responsible for combined pituitary hormone deficiency. Science 1992; 257:1115-1118

11. Ward L, Chavez M, Huot C, Lecocq P, Collu R, Decarie JC, Martial JA, and Van-Vliet G. Severe congenital hypopituitarism with low prolactin levels and age- dependent anterior pituitary hypoplasia: a clue to a PIT-1 mutation. J Pediatr 1998; 132:1036-1038

12. Turton JP, Reynaud R, Mehta A, Torpiano J, Saveanu A, Woods KS, Tiulpakov A, Zdravkovic V, Hamilton J, Attard-Montalto S, Parascandalo R, Vella C, Clayton PE, Shalet S, Barton J, Brue T, and Dattani MT. Novel mutations within the POU1F1 gene associated with variable combined pituitary hormone deficiency. J Clin Endocrinol Metab. 2005; 90: 4762-4770. 